\title{
Synthesis, characterization and in vitro activities of aniline dithiocarbamate crystals
}

\author{
Ayodele T. Odularu' ${ }^{1}$ Peter A. Ajibade ${ }^{2}$, Johannes, Z. Mbese ${ }^{1}$, Opeoluwa O. Oyedeji ${ }^{1}$ \\ ${ }^{1}$ Department of Chemistry, University of Fort Hare, Private Bag X1314, Alice 5700, South Africa. \\ ${ }^{2}$ School of Chemistry and Physics, University of KwaZulu-Natal, Pietermaritzburg, South Africa.
}

201106223@ufh.ac.za/ayodeleodularu@gmail.com

One pot synthesis was used to prepare aniline dithiocarbamate from aniline, carbon(IV) sulfide and sodium hydroxide [1]. Aniline dithiocarbamate crystals (ai-dtc; $\mathrm{C}_{7} \mathrm{H}_{12} \mathrm{NNaO}_{3} \mathrm{~S}_{2}$ ) which grew from solution were washed with diethyl ether, and subjected to single $\mathrm{x}$ ray crystallography. The crystals were collected and mounted on a four circles diffractometer Gemini of Oxford Diffraction, using a graphite monochromated $\mathrm{CuK} \alpha$ radiation $(\lambda=1.54184 \AA)$. Super flip program was used to solve the crystal structure; while refinement was done using full matrix least-squares technique with the support of Jana 2006. The resulting synthetic crystalline structure (Figure 1) appeared as crystalline polymolecule (Figure 2) which has crystal data with three dimensions of a $=2.86663(4) \AA$, $\mathrm{b}=6.9386$ (3) $\AA$ and $\mathrm{c}=11.3127$ (3) $\AA$. Other characterization techniques of physicochemical parameters, FT-IR, UV-Vis and NMR further confirmed ai-dtc structure. [2] For the in vitro antibacterial studies, ai-dtc was screened against four bacterial strains (Staphylococcus aureus MRSA252, Enterococcus faecalis ATCC 19433, Escherichia coli MC4100 and Pseudomonas aeruginosa PAO1). Result showed that ai-dtc had modest activity against Staphylococcus aureus [2].

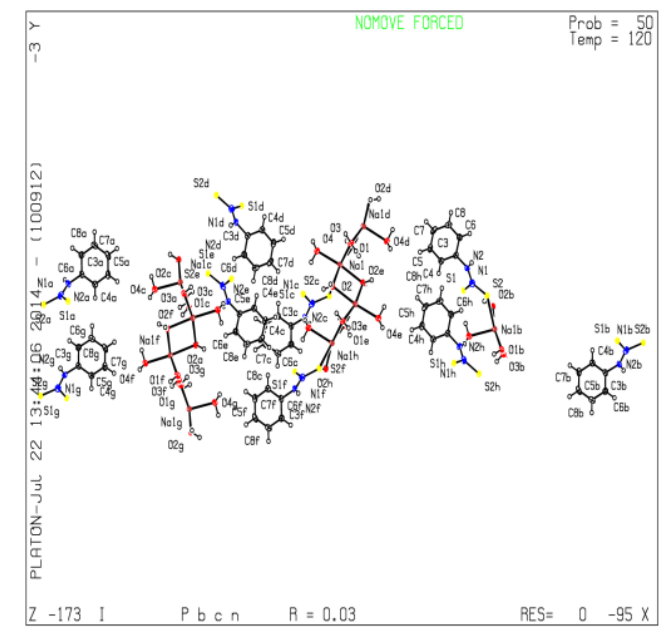

Figure 1: $\mathrm{C}_{7} \mathrm{H}_{12} \mathrm{NNaO}_{3} \mathrm{~S}_{2}$ crystal structure

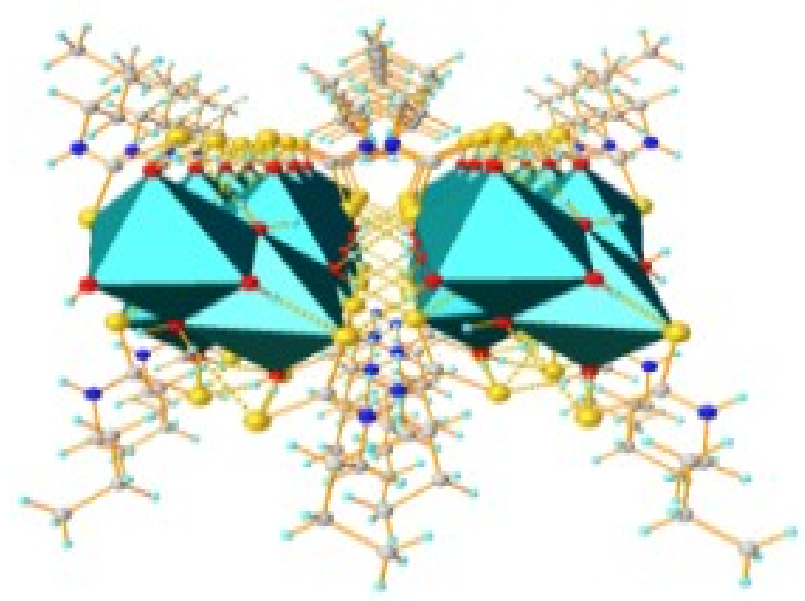

Figure 2: $\mathrm{C}_{7} \mathrm{H}_{12} \mathrm{NNaO}_{3} \mathrm{~S}_{2}$ polymolecule.

[1] Ahamad, M. M.; SureshKumar, E. V.; Rao, R. M.; Phebe, P. Arch. Appl. Sci. Res. 2016, 8, 61-64.

[2] Odularu, A. T.; Ajibade, P. A. Bioinorg. Chem. Appl. 2019, 2019, 1-15.

Keywords: One pot synthesis, dithiocarbamates crystals; polymers; single x-ray crystallography; antibacterial activities 